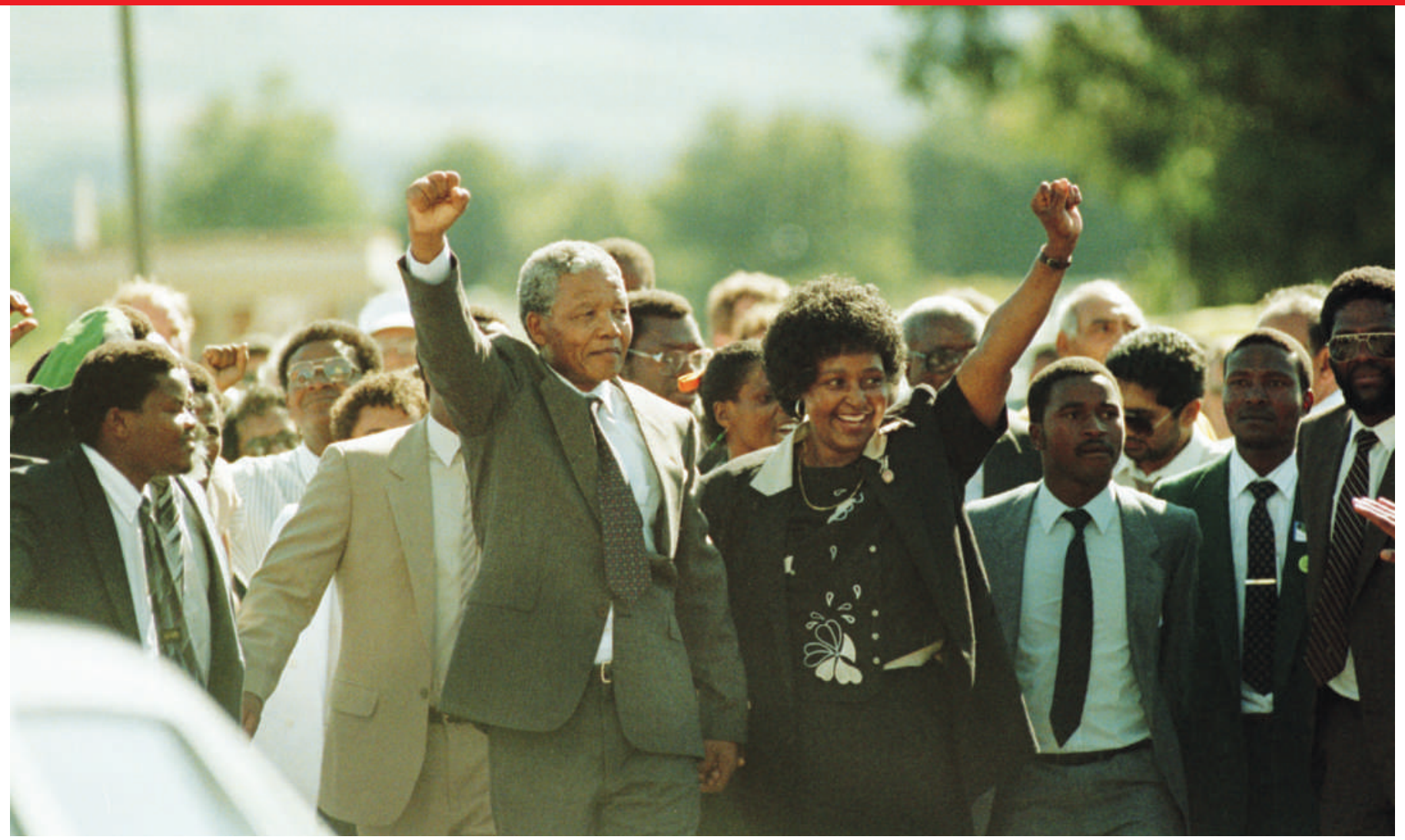

\title{
South African science: black, white and grey
}

\section{The release of Nelson Mandela sent optimism coursing through South Africa's research community. Twenty years on, Michael Cherry finds that it is still struggling to get on its feet.}

W

hen Nelson Mandela was released from prison on 11 February 1990, Carolyn Williamson watched the events on her television in the Canadian province of Newfoundland. Having completed her doctorate a year previously, she was seven months pregnant and being supported by her husband. She listened to the stirring speech — " "apartheid has no future" - that Mandela delivered from the balcony of Cape Town's city hall. "I was very sad not to be there," Williamson says, "and that was the deciding factor in our decision to return home later that year."

Williamson took up a temporary lectureship at the University of Cape Town and, 20 years on, she has no regrets. One of the country's foremost HIV researchers, she runs a thriving group of ten postdoctoral and graduate students that forms part of the university's Institute for Infectious Diseases and Molecular Medicine. "Being back in South Africa has contributed to my success," she says: the country's soaring rates of HIV and tuberculosis have presented research opportunities. But Williamson also knows that she is one of the lucky ones. "The only reason I have been able to survive in terms of research is because I have had international funding," she says. By contrast, a generation of younger researchers is finding it tough to keep labs alive. Botanist Bruce Anderson was a 15-year-old in 1990 and now has a tenured position at Stellenbosch University - but he is surviving on funding of 40,000 rands (US\$5,400) a year from the country's National Research Foundation (NRF). "All I can fund with this are the running costs for my own research and that of a master's student," he says.

The mixed feelings among researchers now are rather different from the optimism they shared when Mandela was released. South Africa was already by far the biggest research base on the continent, with historical strengths in fields such as optical astronomy, geology, botany, zoology, clinical medicine and mining technology. Associated with this base is a set of universities, the best of which are far better than in any other country on the continent. But for many years research had been focused on big applied projects aimed at addressing the isolation of the apartheid era, such as extracting oil from coal, uranium enrichment, and building a national accelerator. Buoyed by political change, researchers who had felt isolated hoped that renewed contact with the outside world would be a stimulus to promote goodquality basic research, rather than projects associated with a state of siege. More than anything else, the reform of the country's education system was expected to unleash a pool of talented students who had been denied opportunities during apartheid.

Lack of strong science leadership, a dearth of funds and a series of well-intentioned but poorly executed schemes have left most of those hopes unrealized. In 1994, the Mandela government established 
a ministry of science, technology, arts and culture; later, under Mandela's successor, Thabo Mbeki, the Department of Science and Technology (DST) split off as a separate ministry. But its spending priorities have been questioned, its efforts to boost student numbers have failed to live up to expectations, and beyond that, many scars of the racially segregated education system remain.

The research community's hopes are now pinned on the new minister of science and technology, Naledi Pandor, who has been in office as part of Jacob Zuma's government for only nine months. A language specialist by training, Pandor has emerged as an enthusiastic advocate for science and technology, and has been refreshingly frank about her ministry not meeting its objectives. Moreover, she agrees with researchers that in the past too much focus has been placed on applied research both under apartheid and by the new governments. "There has been some shift in emphasis to applied as opposed to basic research which we need to correct," she says.

\section{Finding funding}

Research funding in South Africa is a perennial problem. In 1990, the apartheid government was spending $0.61 \%$ of its gross domestic product (GDP) on research and development (R\&D), but at least half of this was in the military sector. Spending started to climb as South Africa entered a boom period, and in 2003, at the inaugural meeting of the African ministerial council on science and technology, the Mbeki government agreed to a target of $1 \%$ of GDP by 2008. In Africa, only Egypt spends more than this, yet the target is still modest compared with, for example, the 27 European Union states, which spent $1.85 \%$ of total GDP in 2007. By 2006, South Africa's spending on R\&D had grown to $0.95 \%$ (see graph). But it dropped slightly in 2007 and the $1 \%$ target seems likely to be missed -2008 figures will be released later this year.

One major problem is that research has lacked a strong advocate in government. For 15 years - until Pandor was appointed last year - the DST was headed by politicians from minority partners in government with the ruling African National Congress, and they lacked the political clout to substantially increase sums allocated to research. Hand in hand with funding problems has been the difficulty of recruiting graduate students. According to the DST, the country awarded $23 \mathrm{PhDs}$ per million population in 2003, which is low compared to other emerging economies (for example, Brazil's 42 or South Korea's 172).

Five years ago, after the appointment of mathematician Mosibudi Mangena as minister for science and technology, the DST and the NRF - the main government agency that funds postgraduate training and university researchers in natural and social sciences jointly launched two schemes to address this situation. One was a programme aimed at increasing the number of PhDs in the country $(1,274$ in 2007 , see graph) to 6,000 by 2018 , and ensuring that half of those remained in science and engineering. The other was the country's research-chair scheme, which is intended to release top researchers from teaching and grant writing by awarding them five-year support packages, including replacement posts in their departments so that they can concentrate on training graduate students.

Heinrich Schwoerer arrived from Germany two years ago to take up a research chair in laser physics at Stellenbosch. Schwoerer, whose research uses very fast spectroscopy to investigate molecular reactions in real time, is delighted with the move. "I have more freedom than I would have in my own country in terms of pursuing my research interests," he says.

But after the first two rounds of appointments in 2006 and 2007, which created a total of 72 chairs, only another 10 have been appointed. The goal of 210 chairs by the end of this year seems unlikely to be met, as the DST has not yet allocated the necessary funds to the NRF.

$\mathrm{PhD}$ recruitment also seems to have faltered. The number of $\mathrm{PhD}$ students supported by the NRF rose by $61 \%$ in 2005 , from 1,360 to 2,186 , after the DST made more funds available. But since then, the increase has stalled. Figures for 2009 are not yet available, but the number of PhDs awarded is expected to be significantly lower than in 2008: last year the DST cut its allocation to the NRF slightly. The department's explanation was that the global economic crisis forced it to slash budgets across the board. Robin Drennan, executive director of governance at the NRF, says that the agency's goal is still to increase the number of PhDs produced, to 6,000 per year by 2025 . "We realize that this is a stretch target," he says. He also points out that the value of graduate studentships was increased in 2008 for the first time in many years, and that this could affect the number of students that can be supported.

To researchers, however, the real reason the department cannot sustain these programmes is no secret: South Africa's democratic government has yet to shed its apartheid-erapredecessor's appetite for 'big science' projects. Seven years ago, the country bid to build the

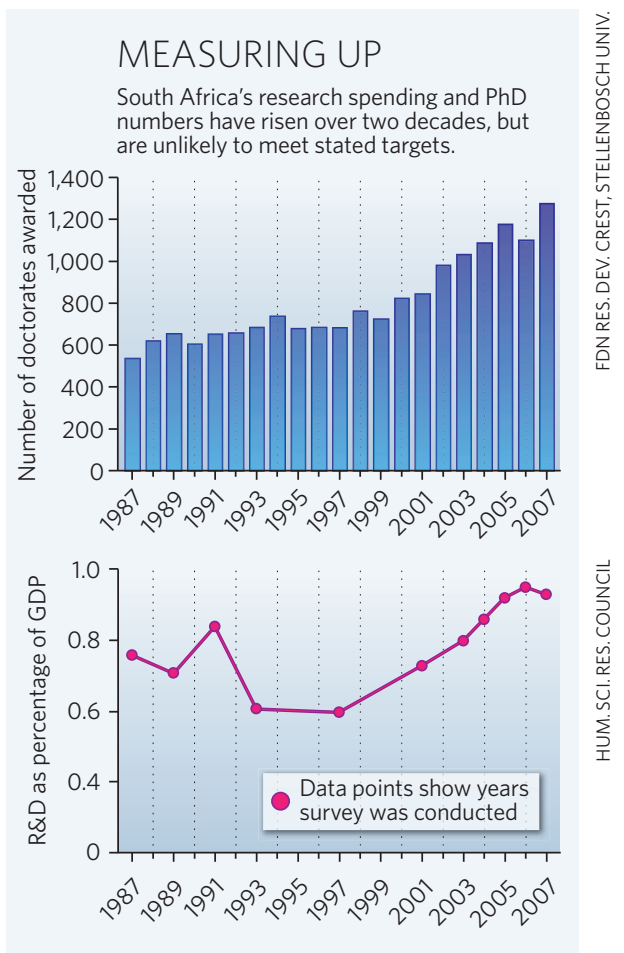

powerful radio telescope called the Square Kilometre Array (SKA). After it was shortlisted with Australia as one of two possible host sites, the DST allocated 1.9 billion rands to the project between 2009 and 2012, mostly towards the construction of a prototype telescope, MeerKAT. This sum, comprising $14 \%$ of the DST's annual budget, is almost three times the current annual allocation to the NRF (680 million rands). If the country wins the bid, the construction cost for the SKA is estimated at more than $\$ 2$ billion. Saul Dubow, a historian at the University of Sussex, UK, who has studied the history of science and apartheid, says the ambition runs counter to the rhetoric of the Mbeki era about the 'Africanization' of science. The country's "aspirations remain thoroughly first world in orientation, and the appeal of prestige projects remains virtually undimmed", he says.

Pandor says that "it is important to have grand challenges and to succeed in addressing these", and that, if South Africa wins the SKA bid, "this would bring a great deal of opportunities to the country". Not all researchers share her conviction, or believe that the country will win the telescope. Phil Charles, director of the South African Astronomical Observatory in Cape Town, says that the sites on offer in South Africa and Western Australia are technically equivalent and that "South Africa's investment in a prototype is a gamble for the jackpot". The gamble wasn't helped when Charles was suspended this month following allegations that he had leaked documents relating to the prototype telescope 
